\title{
Managing knowledge leakage during knowledge sharing in software development organisations
}

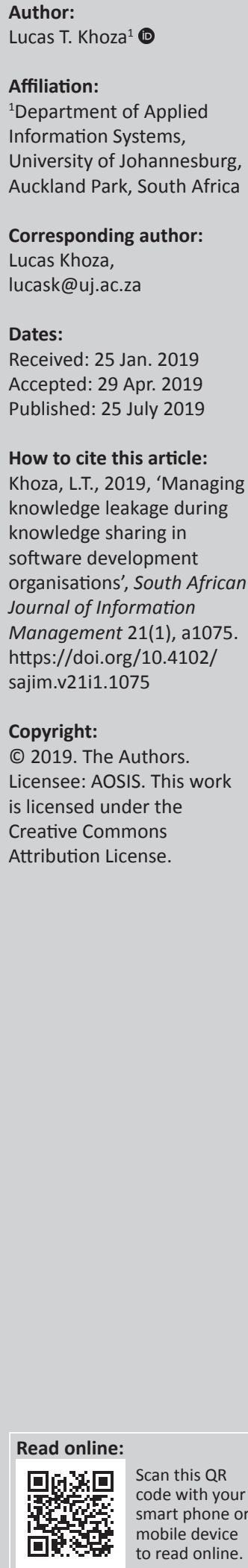

Background: Knowledge refers to the skills and facts that individuals acquire while performing some tasks. Knowledge leakage is the loss of knowledge, resulting in loss of the organisation's position in the marketplace. Internal and external knowledge leakage in software development organisations lowers the organisations' competitive advantage. Knowledge sharing is a process of innovation and value creation that leads to competitive advantage. Innovation is a result of an effective knowledge sharing process. Knowledge can be shared internally and externally; however, not all knowledge can be shared externally because of some confidentiality issues. Some organisations do not promote knowledge sharing to avoid knowledge leakage.

Objectives: The main objective of this study was to investigate how knowledge sharing leads to knowledge leakages in software development organisations.

Method: A structured questionnaire was used to collect data from IT professionals to explore knowledge sharing and knowledge leakages. A response rate of 53.6\% was received.

Results: The results indicated that people always move from one organisation to another, resulting in an increased knowledge leakage. People will always share whatever they have learnt in the new organisation. Five key critical findings that cause staff turnover are management and citizenship, industrial psychology, industrial relations, employee morale and organisational culture.

Conclusions: Because knowledge resides in the brains of individuals, it is recommended that organisations should motivate their staff not to leave. Organisations need to implement global skills resource management, mentoring programmes and documentation of lessons learnt to retain knowledge. Good management strategies should be applied to create a good working environment and organisational culture to retain employees.

Keywords: Knowledge sharing; knowledge leakage; staff turnover; software development organisations, innovation; competitive advantage.

\section{Introduction}

Knowledge refers to the facts and skills that employees acquire while working in their projects (Chatterjee 2014; Koriat \& Gelbard 2014:577). Knowledge leakage is when employees accidentally or purposefully share an organisation's critical internal knowledge to external organisations without permission to do so (Frishammar, Ericsson \& Patel 2015:75; Ritala et al. 2015:22). Knowledge leakage in software development organisations raises some issues more especially for organisations that are competing with each other (Frishammar et al. 2015:76), and lowers their competitive advantage (Koriat \& Gelbard 2014:578; Ritala et al. 2015:23). Employees who move from one organisation to another or staff turnover have a negative impact on knowledge leakage as employees tend to share whatever they have learnt or the skills they have acquired in the new organisation (Ritala et al. 2015:23). Hence, staff turnover leads to 'undesirable knowledge leakage'. Some organisations are limited in their innovation as they do not share their knowledge externally because of unintended knowledge leakage (Ritala et al. 2015:22). There are times when employees accidentally or purposefully leak knowledge obtained from one organisation to another after resigning: this process influences the innovation performance negatively in that organisation that lost knowledge (Frishammar et al. 2015:76; Ritala et al. 2015:29). Collaboration among organisations doing similar business is important in knowledge sharing and can enable both organisations to become influential and stand in a good position (Ritala et al. 2015:22-29). It facilitates the sharing of resources and aids benefits of knowledge integration and specialisation. This raises a question of competitive advantage: how do organisations compete with other organisations that have all the skills and knowledge in running a similar business? (Frishammar et al. 2015:85; Ritala et al. 2015:22-23). There is a risk involved in sharing organisational critical knowledge, 'the undesired 
knowledge sharing', and this can be a major factor hindering external knowledge sharing. Major challenges exist because of cross-business knowledge sharing (Frishammar et al. 2015:76; Ritala et al. 2015:23, 28).

\section{Problem investigated}

Knowledge sharing is vital for organisations to survive today's competitive edge of learning processes. Therefore, projects should concentrate on strategies that enable knowledge sharing and creation (Chatterjee 2014; Pemsel et al. 2014:1411). Knowledge leakages occur in the process of knowledge sharing, which then affects the organisation competitiveness in the market place (Frishammar et al. 2015:86; Ritala et al. 2015:23). The literature indicated publications focusing on knowledge sharing within software development organisations. However, fewer studies focused on knowledge leakages in the process of knowledge sharing during staff turnover, specifically in software development organisations. This research study focuses mainly on knowledge leakages occurring during knowledge sharing in software development organisations.

\section{Research objectives and questions}

The main objective of this research study was to investigate how knowledge sharing leads to knowledge leakage during staff turnover in organisations. The study also investigated the impact of knowledge leakage in organisations that accidentally lost their knowledge. To unpack the research objective, the following research questions were asked:

- What are the factors that contribute to staff turnover during knowledge sharing?

- What are the factors contributing to staff retention?

- How to minimise knowledge leakages during staff turnover?

\section{Literature review}

This section consists of three subsections. Subsection 'Knowledge sharing and factors contributing to staff turnover' addressed factors contributing to staff turnover during knowledge sharing, subsection 'Factors contributing to staff retention' focused on factors contributing to staff retention and subsection 'Knowledge leakages during staff turnover and how to minimise them' focused on knowledge leakages during staff turnover and how to minimise them.

\section{Knowledge sharing and factors contributing to staff turnover}

Employees need to be motivated and encouraged to share knowledge (Khoza \& Pretorius 2017:3; Koriat \& Gelbard 2014:586; Lee, Shiue \& Chen 2016:465; Ritala et al. 2015:24). It has been revealed that any discernment that could help in understanding the factors motivating knowledge sharing in software development teams is likely to improve software project success and the organisation's performance in general (Koriat \& Gelbard 2014:578). Knowledge belongs to employees, and thus knowledge sharing in virtual communities can be hindered by lack of trust (Chang \& Chuang 2011:10; Koriat \& Gelbard 2014:588). With no rewards to compensate employees, the objective to share knowledge will automatically degenerate, resulting in staff turnover when new opportunities arise (Chang \& Chuang 2011:11; Khoza \& Pretorius 2017:7). Knowledge contributors benefit from showing others that they possess valuable expertise, their self-image is improved and they receive recognition as experts (Ritala et al. 2015:25). As a result, these personal benefits are the key motivational factors for individuals to share knowledge (Chang \& Chuang 2011:11). Sometimes knowledge contributors leave organisations if they are not recognised and they will leave with their expertise.

Organisational continuous learning and knowledge sharing enable the organisation to face the market dynamics (Almeida \& Soares 2014:770; Chatterjee 2014). Top management support with proper employee incentive mechanisms facilitate knowledge sharing and motivate employees to share their knowledge, which, in turn, may contribute to project success, thus putting an organisation at a good competitive advantage (Khoza \& Pretorius 2017:3; Lee et al. 2016:466). The effective knowledge sharing among project team members enables an organisation to gain a competitive advantage. The literature reveals that there is still a challenge around the willingness of employees to share their knowledge (Khoza \& Pretorius 2017:5; Ritala et al. 2015:25). Hence, organisations' employees often feel unwilling to share their knowledge because they fear that they might lose their jobs or that their status in the organisation might be jeopardised because of their knowledge sharing (Khoza \& Pretorius 2017:2). Many challenges such as job security, lack of motivation, work overload, lack of communication, psychological factors and resistance to change are key factors that hinder people from sharing knowledge (Khoza \& Pretorius 2017:2-3).

Past research has found that employees' sense of well-being is strongly linked with monetary value (Hau et al. 2013:357; Lin, Wu \& Lu 2012:753-754; Llopis \& Foss 2016:139). Moreover, it is important to share the knowledge that exists among the members of different organisations because it is through such knowledge sharing that organisations can increase their profile in gaining market opportunities, enhancing performance and competing in an uncertain environment (Chumg et al. 2016:432). Some factors that cause employees to leave companies are employees' attitude, organisational culture, job performance, industrial relations, work environment, employee morale, personnel management, industrial psychology, work ethic, management and citizenship (Khoza \& Pretorius 2017:3-4; Koriat \& Gelbard 2014:580). Ghapanchi and Aurum (2011) summarise all the factors into five core factors, namely individual, organisational, job-related, psychological and environmental factors. Organisational culture is just the values and beliefs determining how people interact with stakeholders and how they run their business (Ghapanchi \& Aurum 2011). Hence, 
organisational culture is shaped by the environmental and individual factors as individuals are shaped by their individual cultures. The work environment that is shaped by culture also determines employee morale, the well-being of employees at the workplace. Psychological factors are what drive employees to perform in the workplace, for example motivation, learning and/or attitudes (Ghapanchi \& Aurum 2011; Koriat \& Gelbard 2014:580).

\section{Factors contributing to staff retention}

Knowledge leakage refers to the undesirable, unwanted, loss of knowledge within the boundaries of an organisation causing harm to that organisation as it loses its position of competitive advantage (Frishammar et al. 2015:75; Ritala et al. 2015:22). As IT professionals possess different skills and knowledge that can enhance the success of software projects, it is therefore crucial to motivate the project teams to share their knowledge among each other (Koriat \& Gelbard 2014:577). If project team members are not motivated to share what they know, the organisation might be affected during staff turnover. Companies sometimes employ the services of contractors which results in a high risk of knowledge leakages. Contractors come to do the work they have been hired to do and then they leave when the contract ends. They tend to share the knowledge they have gained with other organisations. Even though contractors pose high knowledge leakages as they share the knowledge gained in other organisations, they can still bring some advantages like flexible employment strategies and support organisational performance (Koriat \& Gelbard 2014:577-578).

The question, maybe, would be what makes employees want to stay in one organisation? Staff retention is important. The literature on knowledge sharing revealed that though knowledge belongs to the organisation, it remains in the minds of employees if not documented. This is the same even for organisations that store their knowledge within their databases; employees will always go with what they know (Ritala et al. 2015:25). There are factors that make employees want to stay in one organisation, such as being paid well, mentored, challenged, promoted, involved, appreciated, valued, being on a mission, empowered and trusted (Harrell 2015; Kovach 1987). External knowledge sharing might be subject to high risks and high benefits depending on the kind of knowledge that is being shared and who shares it for what purpose. Some benefits of external knowledge sharing are to explore the value it can bring to the organisation and the potential markets where the knowledge would be useful. Some organisations desist from external knowledge because of potential risks that are involved and they cannot see the potential and the benefits of external knowledge sharing (Ritala et al. 2015:28). There are challenges in protecting existing knowledge with partners or other industries performing similar business during collaborations. Knowledge sharing, whether internally or externally, might improve the organisation performance irrespective of the risks involved (Frishammar et al. 2015:75; Khoza \& Pretorius
2016). Research has put more emphasis on documenting lessons learnt in organisations to ensure that their IT systems become the centre of an organisation's competitive advantage (Koriat \& Gelbard 2014:577). Software organisations must encourage teamwork where knowledge is shared among team members to utilise their capability to benefit the organisation (Carmeli, Gelbard \& Goldriech 2011; Khoza \& Pretorius 2016, 2017:3).

\section{Knowledge leakages during staff turnover and how to minimise them}

Software development organisations pose multifaceted problems for information and knowledge management because of lack of standardisation of organisational structures, processes, practices and technologies (Almeida \& Soares 2014:770). Hence, the standardisation of organisational processes and practices is crucial. The ineffectiveness of knowledge sharing over time, between project teams, is perhaps the critical issue that software development organisations are dealing with (Almeida \& Soares 2014:770). This strongly affects organisational learning (Chatterjee 2014). Knowledge sharing supports organisational learning. Hence, it is crucial for all project team members to engage in this process. To improve the performance of software development organisations, there is a need for organisations to keep on learning and ensure that all knowledge, experiences and new skills learnt in projects are documented for future use (Chatterjee 2014). Building relationships and trust among project team members helps in knowledge sharing and learning. Khoza and Pretorius (2017:3) argue that people do not share knowledge with people they do not have a good relationship with or they do not trust. Organisational culture and project team members' culture sometimes are conflicting, and this leads to difficulty in knowledge sharing and learning. Therefore, top management needs to build a culture that will enable learning and knowledge sharing. Lessons learnt in each project need to be documented for future reference (Almeida \& Soares 2014:776; Chatterjee 2014).

If knowledge remains within the brains of employees or project team members, the knowledge will result in knowledge leakage when employees resign and leave with the knowledge and it is a loss to the organisation (Almeida \& Soares 2014:770). Therefore, it is advised that at the end of each project, the knowledge created should then be transferred to the organisation as a whole for organisational learning (Chatterjee 2014), and contribute in this way for a common knowledge-basis across projects. Khoza and Pretorius (2017:3) state that knowledge sharing mechanisms can be used to enable proper knowledge sharing across projects and this process helps in learning. IT platforms and their components help people to communicate their knowledge, supporting the organisation to focus on the exchange of ideas between individuals and not knowledge objects in a database, helping to transfer knowledge using, for instance, brainstorming sessions and one-on-one conversations. Moreover, this builds the trust and 
relationships between project members (Almeida \& Soares 2014:776), and thus enables proper organisational learning (Chatterjee 2014).

Documenting knowledge of lessons learnt helps organisations to reuse the knowledge without contacting the person who originated the knowledge (Almeida \& Soares 2014:776). The employee's expertise and knowledge in their brain does not benefit the organisation after they have resigned unless the knowledge was documented. The creation of new knowledge is vital. Organisations can use knowledge sharing mechanisms and tools to improve their performance and increase customer value (Lee et al. 2016:464). Knowledge sharing can also be linked to learning and improvements in markets as well as innovation (Chatterjee 2014; Wang \& Wang 2012:8899). Durst and Ferenhof (2014) propose programmes that can be used in organisations to minimise knowledge leakage, such as making use of global skills resource management, employee rotational programmes, sharing case studies of lessons learnt, using communities of practice, storytelling, training and educating programmes, strengthening recruiting relationships, creating a knowledge manager position, hiring retirees and using mentoring programmes.

\section{Research design and methodology}

When considering that this research study focused on exploring knowledge leakages during knowledge sharing in software development organisations, a quantitative approach was deemed fit for this research. A structured questionnaire consisting of four sections was used for this study. Section 1 of the questionnaire used in this research study focused on bibliographic information; section 2 addressed factors contributing to staff turnover during knowledge sharing; section 3 focused on factors contributing to staff retention and section 4 focused on knowledge leakages during staff turnover and how to minimise them. Respondents were asked to respond by indicating level of agreement on a 5-point Likert scale ranging from 'strongly agree' to 'strongly disagree'. Data used in this research study were collected from four software development organisations listed in the Johannesburg Stock Exchange (JSE) in South Africa. A total number of 218 questionnaires were sent to the four organisations and a total number of 117 (53.6\%) questionnaires were returned. The population for this study mainly consisted of IT professionals within the selected software development organisations. Expert sampling was used as a sampling method because the interest was to get insights from professionals within the field. SPSS version 20 was then used to analyse the collected data. Lastly, tests for internal consistency were used to increase the reliability and the validity of the results.

\section{Results}

\section{Bibliographic profile of respondents}

The demographic profile of respondents is only limited to gender, position, years of experience and highest qualification. Table 1 summarises the results. Sixty-seven per cent of the respondents were male, while the remaining $33 \%$ were female. IT specialists who participated in this research study are business analysts (18.80\%), system testers $(25.64 \%)$, database administrators $(17.09 \%)$, project managers (8.55\%) and programmers (24.79\%). Only people who had an experience of more than a year were eligible to participate. The results indicate that the majority of the respondents have undergraduate qualifications $(58.97 \%)$.

\section{Factors contributing to staff turnover}

This research study discussed briefly that staff turnover results in knowledge leakages. Figure 1 shows the different factors contributing to staff turnover. Management and citizenship contribute $55 \%$ towards staff turnover. These results could mean that people are not leaving the organisations but their managers. Industrial psychology and industrial relations contributed $52 \%$ and $45 \%$, respectively. The results are confirmed by the studies of Koriat and Gelbard (2014:580). Employee morale and organisational culture also contribute to staff turnover. It is

TABLE 1: Demographic profile of respondents.

\begin{tabular}{llc}
\hline Variable & Profile & $\mathbf{\%}$ \\
\hline Gender & Male & 66.7 \\
& Female & 33.3 \\
Position & Business analyst & 18.8 \\
& Systems testers & 25.64 \\
& Database administrators & 17.09 \\
& Project managers & 8.55 \\
Years of experience & Programmers & 24.79 \\
& $1-5$ & 28.21 \\
& $6-10$ & 34.19 \\
& $11-20$ & 24.79 \\
Highest qualification & $>20$ & 12.82 \\
& Matric & 5.98 \\
& Degree/Diploma & 58.97 \\
& Postgraduate & 34.19 \\
& Other & 0.85 \\
\hline
\end{tabular}

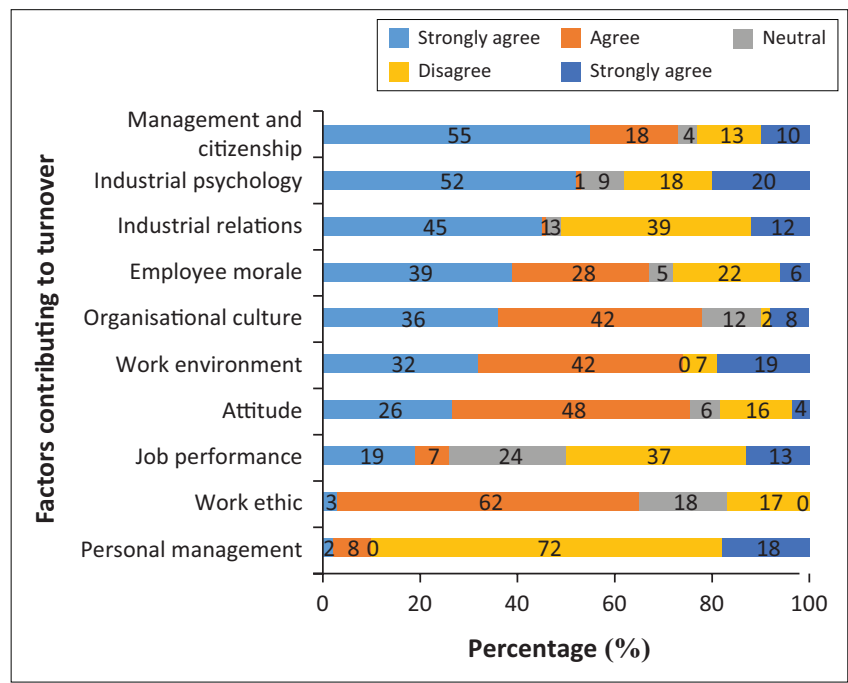

FIGURE 1: Factors contributing to staff turnover. 
important for organisations to create a good working environment with a good organisational culture to create employee morale. If all these factors contributing to staff turnover are not addressed, organisations will lose their knowledge and forfeit their positions in the market. The results are read from right to left, from strongly agree to strongly disagree.

\section{Factors contributing to employee retention}

Employees will always want to stay in organisations when the employer meets their expectations. This article revealed several factors that make employees want to stay. Figure 2 shows the results of what employees really expect from organisations. It is clear from the results that employees stay when they are paid well $(82 \%)$, mentored $(64 \%)$, valued $(60 \%)$, promoted $(59 \%)$ and trusted $(53 \%)$. These top five factors can attract good employees within the organisations and can also be a good form of staff retention. Kovach (1987) and Harrell (2015) argue that employees can do anything when they are paid well and it will be easy for them to even share their knowledge. Khoza and Pretorius (2017:8) further argue that people will always share their knowledge with people they trust; hence, trust is important. The results are read from right to left, from strongly agree to strongly disagree.

Table 2 indicates the latent construct (factors making employees want to stay in organisations) and the test for internal consistency. Factors are measured reliable when the Cronbach's alpha values are 0.7 or higher. Cronbach's alpha, with a cut-off point of 0.7 , was used to test for internal consistency. These results show that these factors are key drivers for employees to stay in organisations.

How much effort does it take to replace experienced staff members? It costs a company to drop from their competitive position in the market because of staff turnover, and therefore staff retention is crucial. Management should always try to meet the expectations of their employees. Figure 3 shows the relationships between retired or resigned staff, newly hired and rehired staff from 2007 to 2017. The results pose an interesting argument, which highlights that the level of staff turnover is high and increased from 2016 to 2017. These results also reveal that people who either resigned or retired in 2009, 2010, 2012, 2014, 2016 and 2017 are more compared with newly hired employees. These results could be an indication of lacking the elements of staff retention in software development organisations. It is more difficult and time-consuming to hire new skilled and experienced employees than to retain employees. Another interesting argument to be noted is that some employees are rehired after they have resigned or retired. Khoza and Pretorius (2017:8) indicated that some employees do not share their knowledge because of job security as they always want to retain their positions; hence, the results indicate that some people come back to organisations as consultants to make more money.

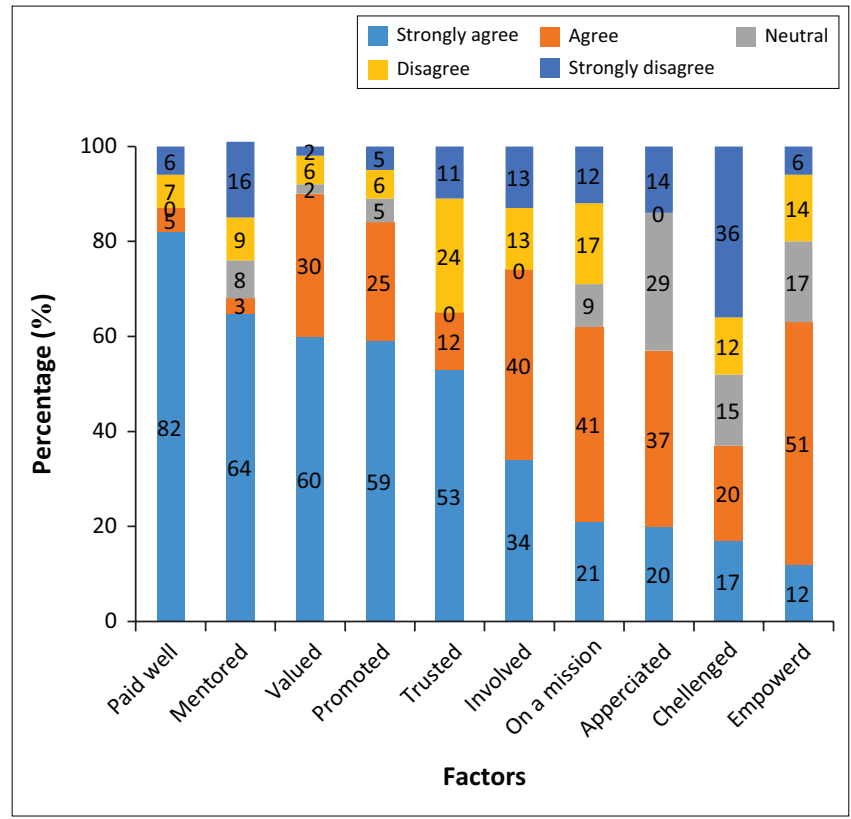

FIGURE 2: Factors making employees want to stay in organisations.

TABLE 2: Test for internal consistency.

\begin{tabular}{lc}
\hline Factors making employee want to stay & Cronbach's alpha \\
\hline Paid well & 0.8915 \\
Mentored & 0.8917 \\
Valued & 0.8974 \\
Promoted & 0.8853 \\
Trusted & 0.8894 \\
Involved & 0.8881 \\
On a mission & 0.8874 \\
Appreciated & 0.8872 \\
Challenged & 0.9324 \\
Empowered & 0.9353 \\
\hline
\end{tabular}

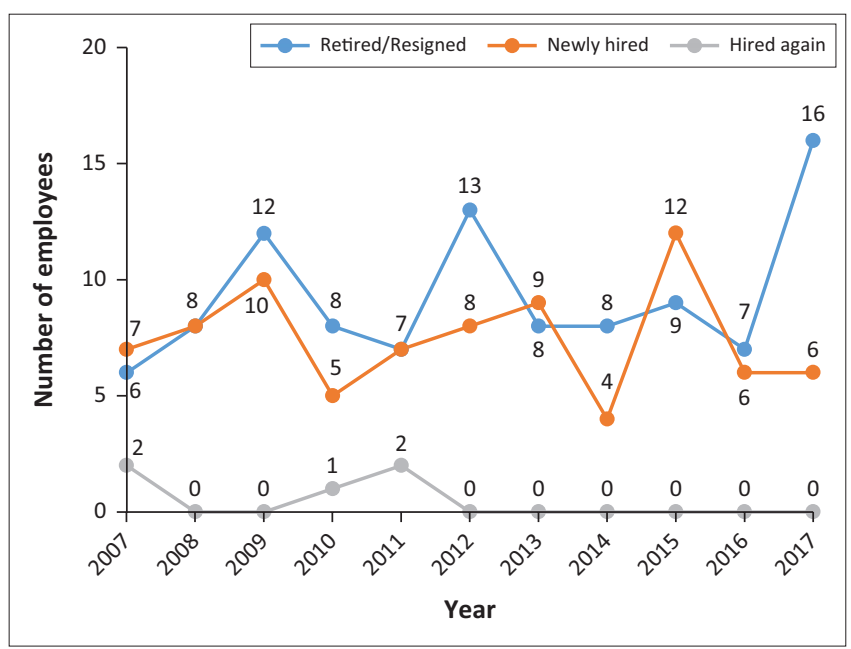

FIGURE 3: Relationship between employees resigning, hired, and rehired.

\section{Knowledge leakages during staff turnover and how to minimise them}

There are different ways to minimise knowledge leakages to ensure that knowledge remains within the organisation. The critical thing is to ensure that knowledge does not only reside in the brains of employees but within the organisations. Figure 4 shows different knowledge retention programmes. Looking at 


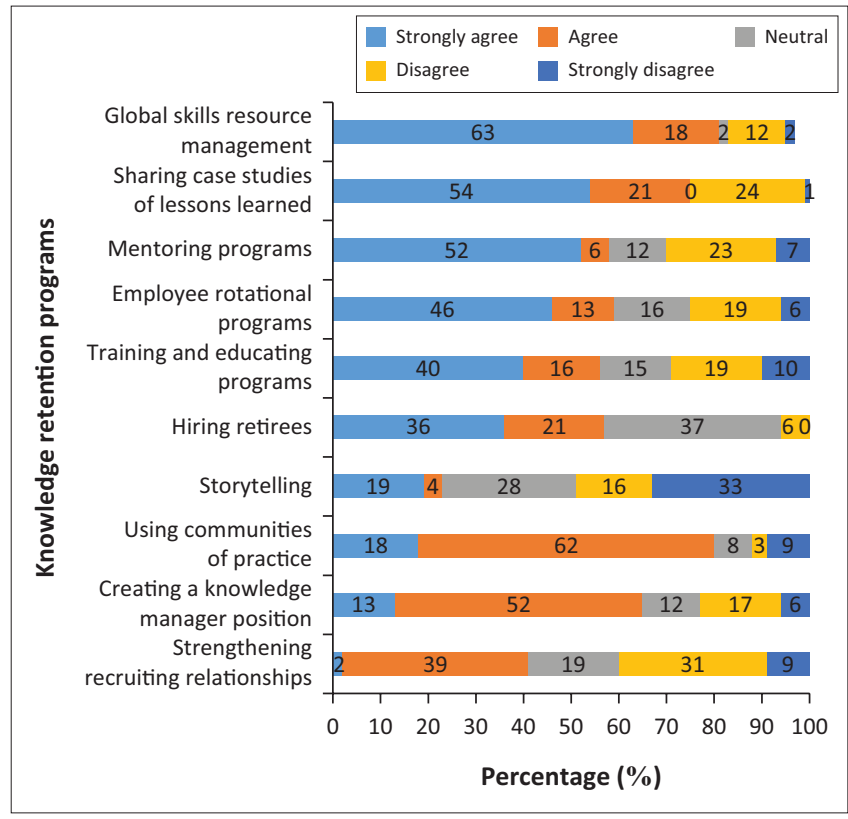

FIGURE 4: Knowledge retention programs.

the top five employee retention programmes: global skills resource management $(63 \%)$ is where companies hire highly skilled consultants to work in critical projects and also share their expertise and knowledge to the internal full-time employees, the process of sharing case studies of lessons learnt (54\%) will help the entire team to learn from each team member about what they have learnt and the important thing is to document all lessons learnt to benefit the organisation, mentoring programmes (52\%), employee rotational programmes (46\%) and training and education programmes (40\%). The results are read from right to left, and from strongly agree to strongly disagree.

\section{Managerial implications and future research directions}

Some employees move from one organisation to another and cause knowledge leakages not because they hate the organisations they are working for but because managers do not motivate them to stay. Managers should create a good working environment to make all employees feel valued, welcomed and as if they are part of the organisation. To hire a skilled employee is more difficult than to retain an existing skilled employee. To avoid staff turnover and knowledge leakages, managers should retain and meet the needs of their employees.

Future study can focus on the refinement of the questionnaire and hypothesise the results to find the relationship between employee retention and staff turnover. Interviews can be conducted to compare literature insights. Lastly, future studies can investigate the efforts of hiring skilled employees who left the organisations to help the organisation in maintaining competitive advantage.

\section{Conclusion}

This study has revealed several factors on how knowledge leakages can jeopardise the position of the organisation in the market. It was discussed that knowledge leakages are results of staff turnover. Results revealed some retention methods for organisations to use to retain key employees, for example employees stay when they are paid well, mentored, involved, valued and promoted. The best way to retain skilled employees within organisations is to ensure that their needs are met. The documentation of skills and knowledge acquired during projects is very important for future learning of the organisation. Organisations need to implement global skills resource management, mentoring programmes and documentation of lessons learnt to retain knowledge. Good management strategies should be applied to create a good working environment and organisational culture to retain employees. Based on the findings, it is recommended that critical organisational knowledge should not be shared with anyone, but be kept for competitive advantage of the organisation.

\section{Acknowledgements Competing interests}

The author declares that no competing interests exist.

\section{Author's contributions}

I declare that I am the sole author of this research article.

\section{Funding}

This research received no specific grant from any funding agency in the public, commercial, or not-for-profit sectors.

\section{Data availability statement}

Data sharing is not applicable to this article as no new data were created or analysed in this study.

\section{Disclaimer}

The views and opinions expressed in this article are those of the author and do not necessarily reflect the official policy or position of any affiliated agency of the author.

\section{References}

Almeida, M.V. \& Soares, A.L., 2014, 'Knowledge sharing in project-based organizations: Overcoming the informational limbo', International Journal of Information Management 34(6), 770-779. https://doi.org/10.1016/j.jijinfomgt.2014.07.003

Carmeli, A., Gelbard, R. \& Goldriech, R., 2011, 'Linking perceived external prestige and collective identification to collaborative behaviors in R\&D team', Expert Systems with Applications 38(7), 8199-8207. https://doi.org/10.1016/j.eswa.2010.12.166

Chang, H.H. \& Chuang, S.S., 2011, 'Social capital and individual motivations on knowledge sharing: Participant involvement as a moderator', Information \& Management 48(1), 9-18. https://doi.org/10.1016/j.im.2010.11.001

Chatterjee, S., 2014, Managing constraints and removing obstacles to knowledge management, viewed 16 March 2018, from https://mpra.ub.uni-muenchen. de/57789/.

Chumg, H.F., Seaton, J., Cooke, L. \& Ding, W.Y., 2016, 'Factors affecting employees' knowledge-sharing behaviour in the virtual organisation from the perspectives of well-being and organisational behaviour', Computers in Human Behavior 64 $432-448$, viewed n.d., from https://search.proquest.com/openview/f8c901fc6b2 031d4c45f7c66e9489be7/1?pq-origsite=gscholar\&cbl=1796412.

Durst, S. \& Ferenhof, H.A., 2014, 'Knowledge leakages and ways to reduce them in small and medium-sized enterprises (SMEs)', Information 5(3), 440-450. https:// doi.org/10.3390/info5030440

Frishammar, J., Ericsson, K. \& Patel, P.C., 2015, 'The dark side of knowledge transfer: Exploring knowledge leakage in joint R\&D projects', Technovation 41, 75-88. https://doi.org/10.1016/j.technovation.2015.01.001 
Ghapanchi, A.H. \& Aurum, A., 2011, 'Antecedents to IT personnel's intentions to leave: A systematic literature review', Journal of Systems and Software 84(2), 238-249. A systematic literature review', Journal of
https://doi.org/10.1016/j.jss.2010.09.022

Harrell, J., 2015, 'What makes employees to stay?' viewed 08 February 2018, from https://www.linkedin.com/pulse/employees-stay-when-jason-harrell/.

Hau, Y.S., Kim, B., Lee, H. \& Kim, Y.G., 2013, 'The effects of individual motivations and social capital on employees' tacit and explicit knowledge sharing intentions', International Journal of Information Management 33(2), 356-366. https://doi.org/10.1016/j.ijinfomgt.2012.10.009

Khoza, L.T. \& Pretorius, A.B., 2016, 'Knowledge sharing in software development projects', in International Conference on Intellectual Capital and Knowledge Management and Organisational Learning (p. 143), Academic Conferences International Limited, viewed 23 September 2018, from https://search proquest.com/openview/9bbd2937c532941ac029d7ba84bde8e2/1?pqproquest. com/openview $/ 9 \mathrm{~b}$
origsite=gscholar \&cbl=1796420

Khoza, L.T. \& Pretorius, A.B., 2017 'Factors negatively influencing knowledge sharing in software development', South African Journal of Information Management 19(1), 1-9. https://doi.org/10.4102/sajim.v19i1.776

Koriat, N. \& Gelbard, R., 2014, 'Knowledge sharing motivation among IT personnel: Integrated model and implications of employment contracts', International Journal of Information Management 34(5), 577-591. https://doi.org/10.1016/j. Journal of Information
Kovach, K.A., 1987, 'What motivates employees? Workers and supervisors give different answers', Business Horizons 30(5), 58-65.

Lee, J.C., Shiue, Y.C. \& Chen, C.Y., 2016, 'Examining the impacts of organizational culture and top management support of knowledge sharing on the success of
software process improvement', Computers in Human Behavior 54, 462-474. https://doi.org/10.1016/j.chb.2015.08.030

Lin, T.C., Wu, S. \& Lu, C.T., 2012, 'Exploring the affect factors of knowledge sharing behavior: The relations model theory perspective', Expert Systems with Applications 39(1), 751-764. https://doi.org/10.1016/j.eswa.2011.07.068

Llopis, O. \& Foss, N.J., 2016, 'Understanding the climate-knowledge sharing relation: The moderating roles of intrinsic motivation and job autonomy', European Management Journal 34(2), 135-144. https://doi.org/10.1016/j.emj.2015.11.009

Pemsel, S., Wiewiora, A., Müller, R., Aubry, M. \& Brown, K., 2014, 'A conceptualization of knowledge governance in project-based organizations', Internationa Journal of Project Management 32(8), 1411-1422. https://doi.org/10.1016/j ijproman.2014.01.010

Ritala, P., Olander, H., Michailova, S. \& Husted, K., 2015, 'Knowledge sharing, knowledge leaking and relative innovation performance: An empirical study', Technovation 35, 22-31. https://doi.org/10.1016/j.technovation.2014.07.011

Wang, Z. \& Wang, N., 2012, 'Knowledge sharing, innovation and firm performance', Expert Systems with Applications 39(10), 8899-8908. https://doi.org/10.1016/j. eswa.2012.02.017 